\title{
Antibiotic resistance pattern and identification of Extended -Spectrum Beta- Lactamase producing Gram-Negative Bacteria obtained from patients admitted in educational hospitals of Shohada Qaen
}

\author{
Zohre Barzegari Esfeden $^{1}(\mathbb{D})$, Ali Ghaderi ${ }^{2}(\mathbb{D})$, Ali Dashtgard ${ }^{3}(\mathbb{D})$, Marzie Moghanni ${ }^{4}$ \\ ${ }^{1}$ Public Health Department, Birjand University of Medical Sciences, Qaen School of Nursing and Midwifery, Birjand, Iran. \\ ${ }^{2}$ Expert Medical Laboratory of shohada Hospital of Qaen, Birjand University of Medical Sciences, Birjand, Iran. \\ ${ }^{3}$ Nursing Department, Birjand University of Medical Sciences, Qaen School of Nursing and Midwifery, Birjand, Iran. \\ ${ }^{4}$ Corresponding Author: Expert of Microbiology Laboratory, School of health, Birjand University of Medical Sciences, Birjand, Iran.:
}

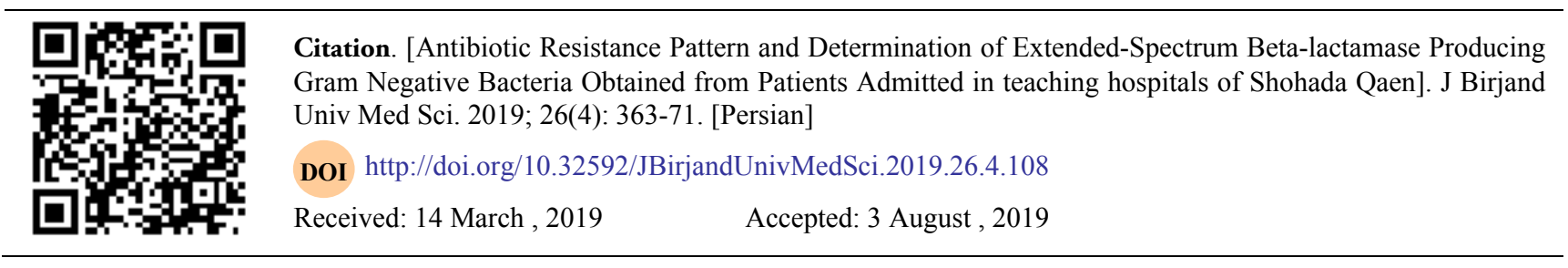

\begin{abstract}
Background and Aim: Determination of antibiotic resistance pattern and awareness of current resistance in each region, it can help to take appropriate therapeutic measures. The purpose of this study to identification of bacterial agents causing infection, and was the determination of their antibiotic resistance in patients admitted to educational hospital of Shohada Qaen, through the years 20182019.

Materials and Methods: In this descriptive-analytic study, in the period of one year, 1980 samples were collected from patients admitted to educational hospitals of Shohada Qaen. The specimens were cultured in blood agar and EMB, and were incubated at $37^{\circ}$ $\mathrm{C}$ for 24 hours, then the infection-causing bacteria were identified by differential biochemical tests, depending on gram positive or gram negative bacteria. The Disk diffusion method was applied to determine antibiotic resistance pattern, and the combined disk phenotypic method was applied to determine the strains producing e extended -spectrum beta-lactamase enzymes (ESBLs).

Results: of 1980 samples collected from patients admitted, 183 bacterial isolates were collected from which 151 gram negative and 32 gram-positive bacteria were identified. The most common isolated bacteria were Escherichia coli with a frequency of $60.1 \%$, followed by Staphylococcus aureus and Klebsiella, with a frequency of $11.5 \%$ and $10.9 \%$ respectively. Generally, gram-positive bacteria had the least resistance to Ciprofloxacin and Imipenem and gram-negative bacteria had the least resistance to Amikacin. $44.7 \%$ of the gram-negative bacteria produced ESBL.
\end{abstract}

Conclusion: Antibiotic administration based on the antibiotic resistance pattern can be more effective and useful. The high prevalence of ESBL producing strains indicates the necessity of rapid monitoring and identification of these strains.

Key Words: Hospital-Acquired Infection; Antibiotic Resistance; Extended Spectrum Beta-Lactamas 
مقاله اصيل ثزوهشى

\section{الكَوى مقاومت آنتىبيوتيكى و شناسايى باكترىهاى ترم منفى توليدكننده بتالاكتاماز هاى وسيع الطيف جداشده از بيماران بسترى در مركز آموزشى و درمانى شهداى قاين}

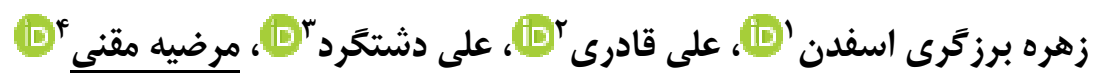

جکكيده

زمينه و هدف: تعيين الكَوى مقاومت آنتى يبوتيكى و آَاهى از مقاومتهاى رايج در هر منطقه، مىتواند به اتخاذ تدابير درمانى مناسب كمى كند.

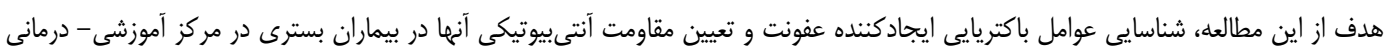

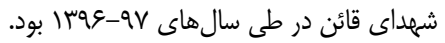

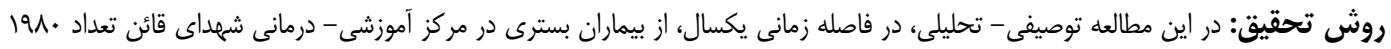

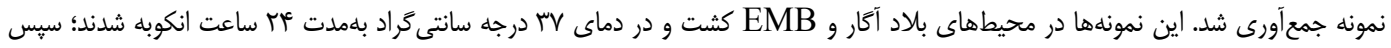

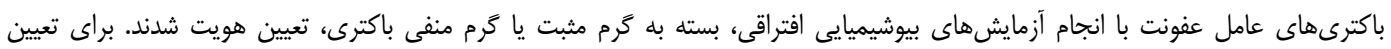

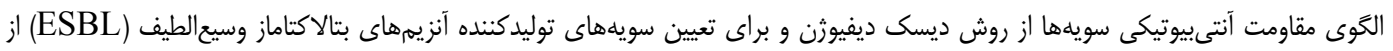

$$
\text { روش فنوتيبى ديسك تركيبى استفاده شد. }
$$

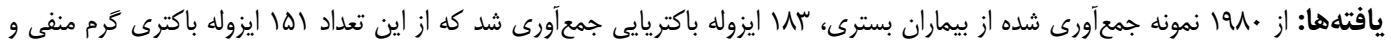

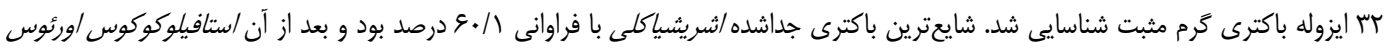

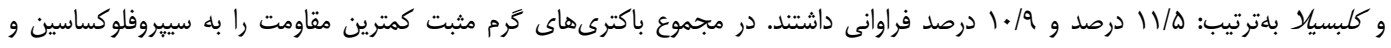

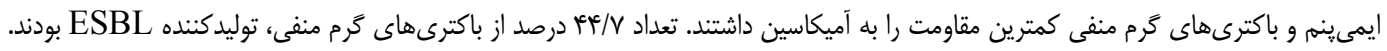

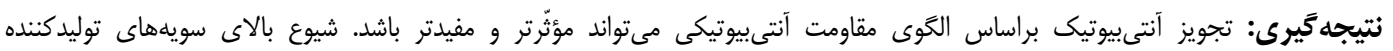
ESBL وازههاى كليدى: عفونت بيمارستانى؛ مقاومت آنتىبيوتيكى؛ بتالاكتاماز وسيع الطيف

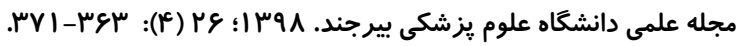

$$
\text { دريافت: سr/T/M }
$$

' كرووه بهداشت عمومى، دانشكده يرستارى و مامايى قاين، دانشكاه علوم يزشكى بيرجند، بيرجند، ايران.

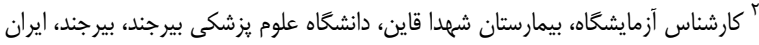

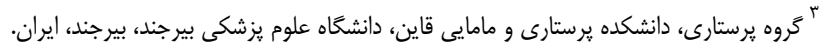

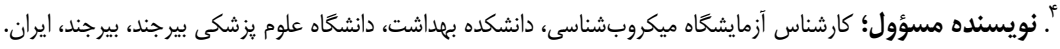

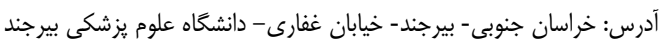

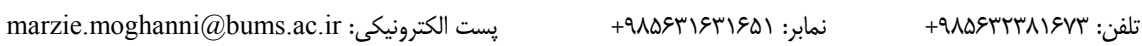


تبالاكتامازهاى وسيعالطيف (-) Extended Spectrum (lactamase; ESBL بتالاكتاماز هستند. در واقع ويزگى منحصر به فرد اين آنزيمها،

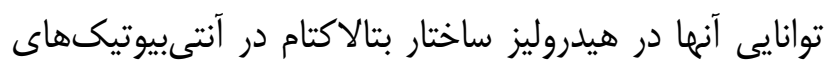

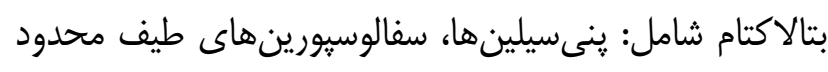

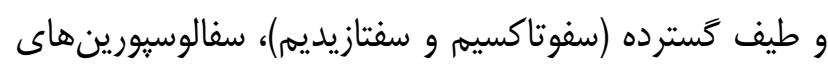

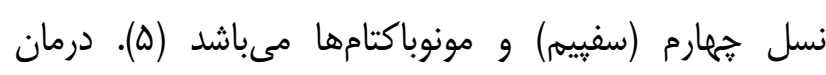

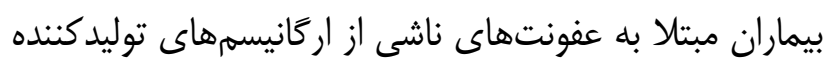
ESBL داروهاى ضدّ ميكروبى از جمله: آمينوكليكوزيدها، كوتريموكسازول و فلوروكينولونها دارند، همواره با مشكلات

فراوانى همراه بوده است (צ).

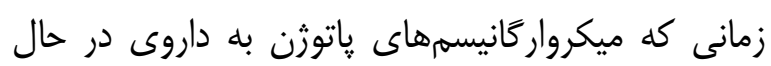

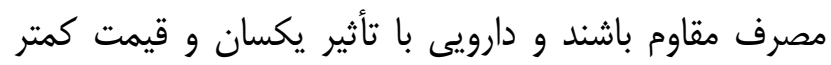

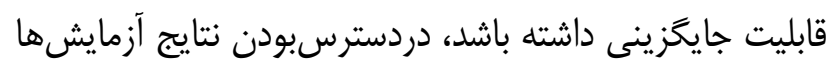
تعيين حساسيت نسبت به آنتىبيوتيكها به تنظيم يا تعديل

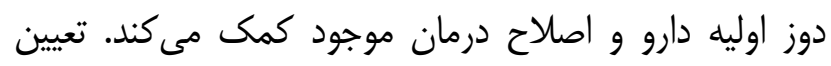

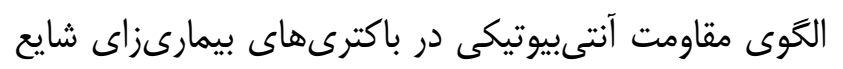
براى هدايت درمانهاى تجربى و اختصاصى عليه ياتوزنهاى

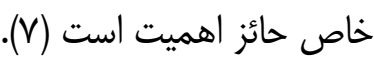

با توجه به اينكه بروز مقاومتهاى آنميت آتتىبيوتيكى در ميان

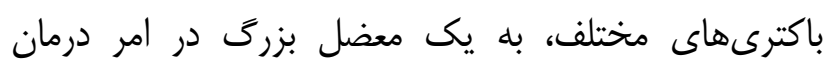

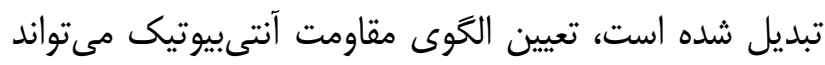

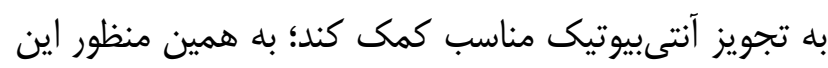

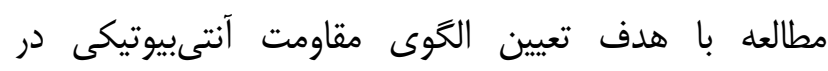

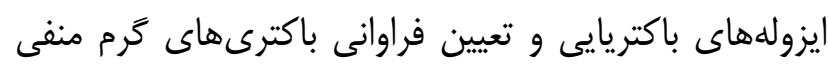

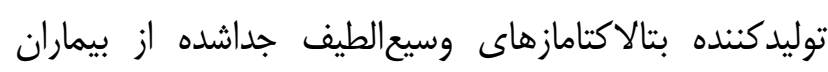
بسترى در مركز آموزشى و درمانى شهداى قاين در طى طى سالهاى Vو-عوسا صورت كرفت.

روش تحقيق در اين مطالعه توصيفى- تحليلى، كليه نمونه دواى مقلdمه

عفونتهاى بيمارستانى، يكى از مهمترين عوامل مرگ و مونه

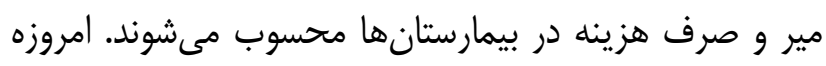

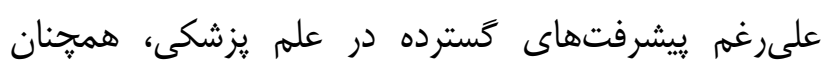
آلودگى ميكروبى بخشهاى مختلف بيمارستانى و عوارض

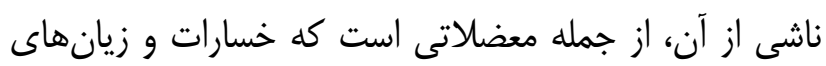

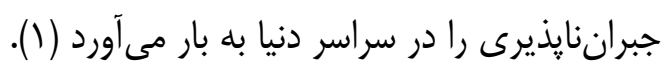

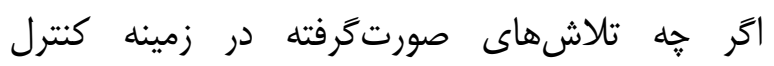
عفونتهاى بيمارستانى با موفقيتهايى همراه بوده است، اما

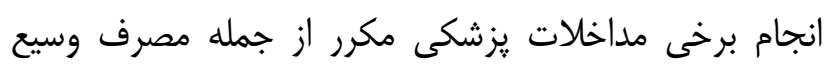

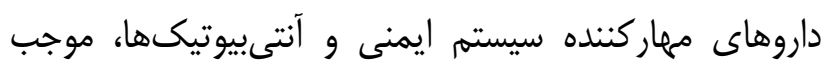

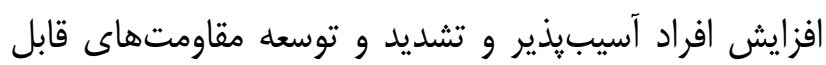

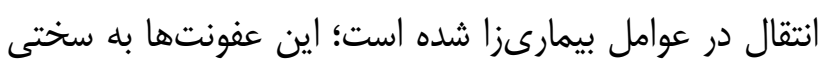

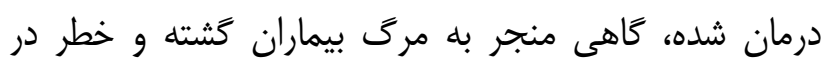
حال افزايش محسوب مى شوند (r).

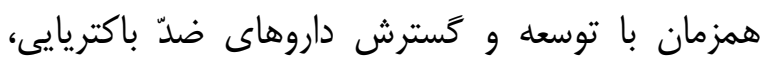
باكترىها نيز روشهاى مختلف مقاومت را بروز دادند. با توسعة دان وجود تلاشهاى بسيارى كه براى ريشه نيز ركنى بيمارى مهاى

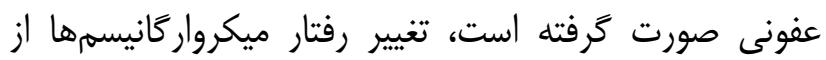
جنبههاى مختلف موجب شده كه ريشهكنى بسيارى از اين عوامل ميكروبى با موفقيت كافى همراه نباشد و حتى با ظهيل نهور

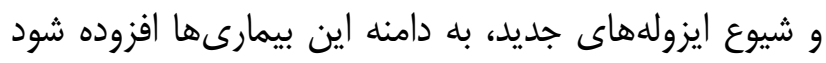

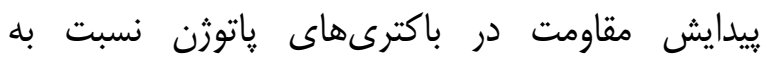
آنتىبيوتيكها، يكى از مشكلات درمانى در سراسر دنياست.

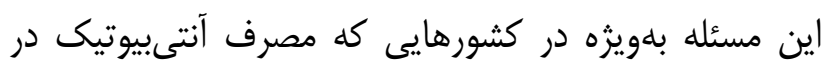

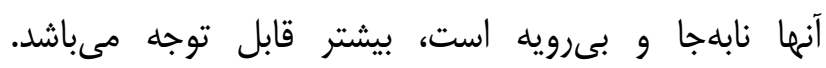

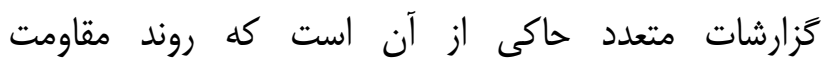
أنتىبيوتيكى در نقاط مختلف دنيا بلهصورت جدى منى بردى إنى

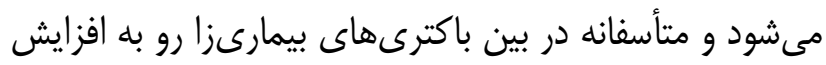

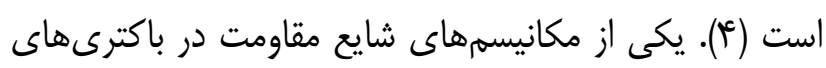

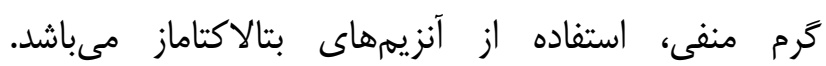


تركيبى 5mm از قطر هاله عدم رشد اطراف ديسك منفرد

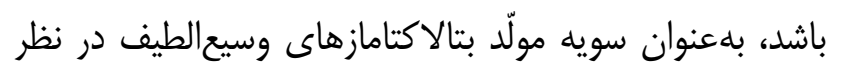

$$
\text { كر فتنه مى شود. }
$$

\section{تجزيه و تحليل آمارى:}

براى تجزيه و تحليل نتايج، از نرمافزار SPSS كنيل (ويرايش

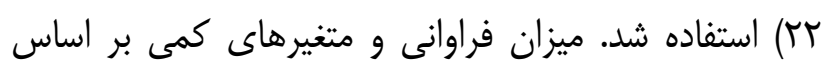

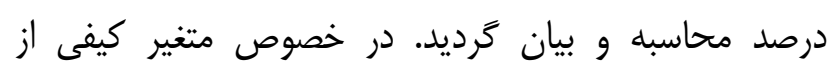

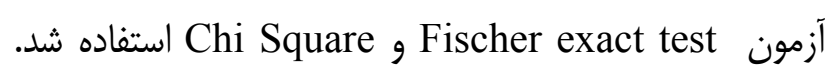

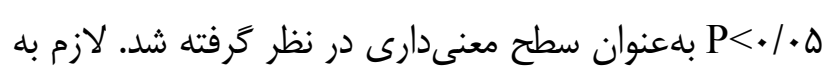

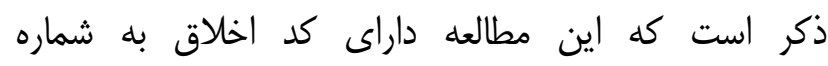
IR.Bums.REC.1396.5

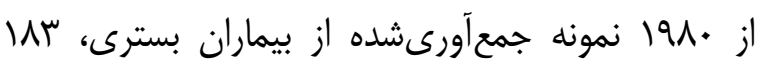

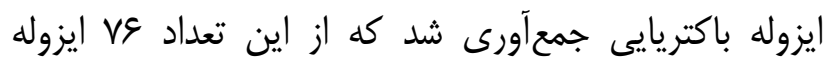

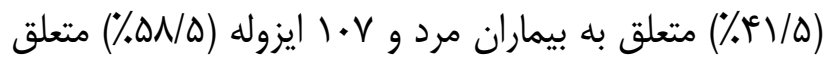

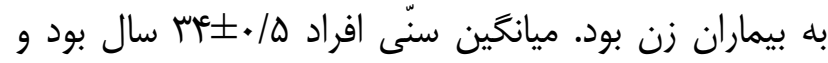

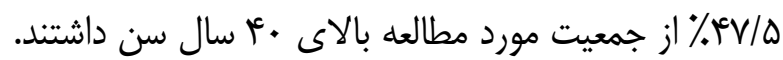

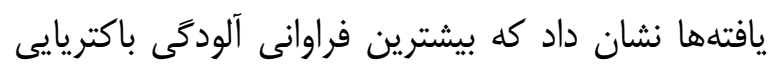

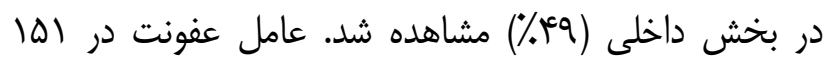
نفر (ه/ه/A

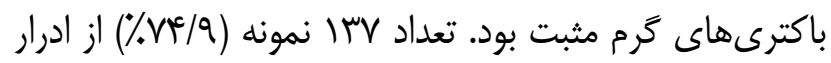

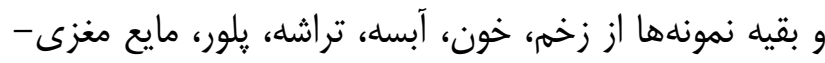

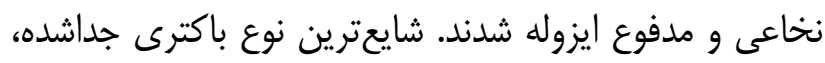

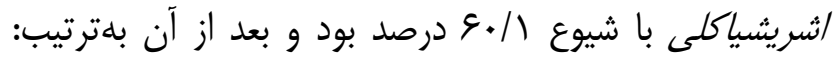

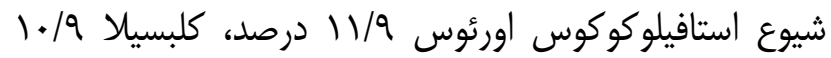

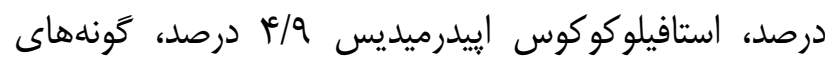

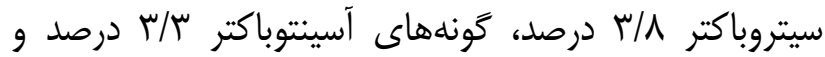

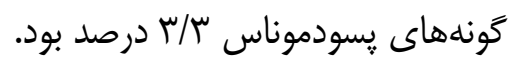

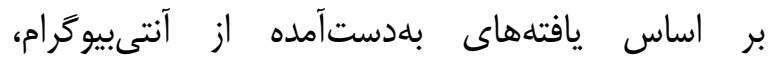
باكترىهاى كرم مثبت بدون توجه به جنس باكترى بيشترين

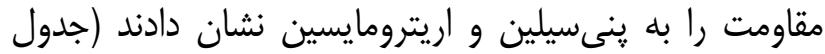

كلينيكى (ادرار، خون، ترشحات، آبسه، زخم و ...) بيماران

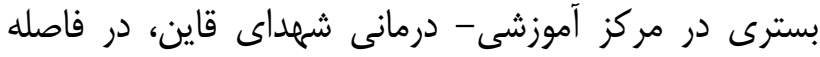

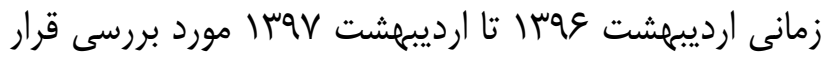

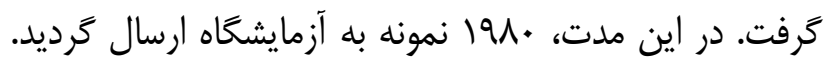

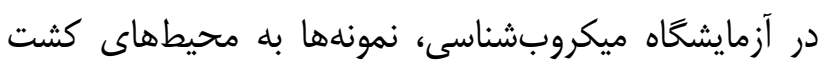
بلاد آكًار و ائوزين متيلن بلو (EMB (Merck آلمان) تلقيح

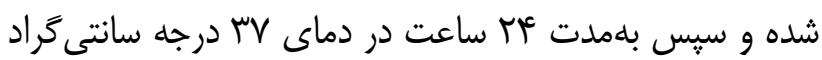

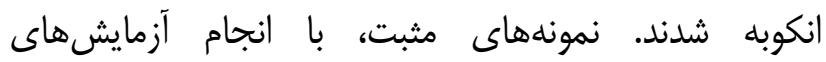

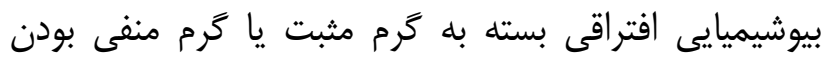
باكترى، تعيين هويت شدند.

\section{تعيين مقاومت آنتىبيوتيكى:}

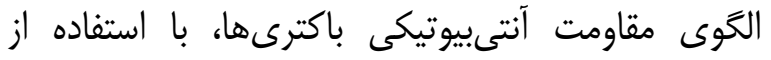

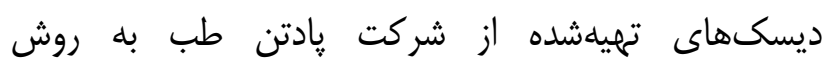
Kirby-Bauer و بر اساس استانداردهاى CLSI سنجيدان

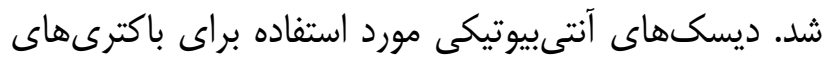

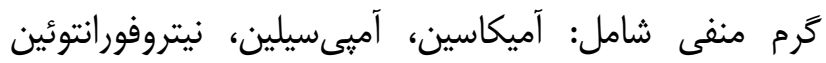
(فقط براى ايزولههاى ادرارى)، كوتريموكسازول، جنتامايسين،

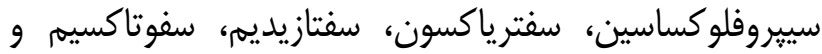
سفازولين و ديسكهاى مورد استفاده براى كرم مثبتهائها

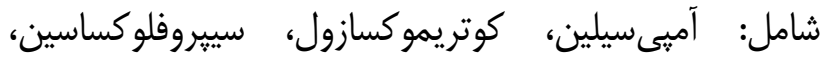

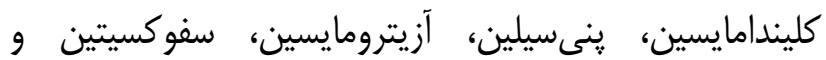

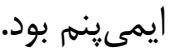

شناسايى باكترىهاى ترم منفى توليدكننده ESBL:

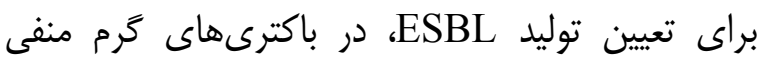
مقاوم به هر يك از آنتىبيوتيكهاى سفتازيديم، سفوتاكسيميا

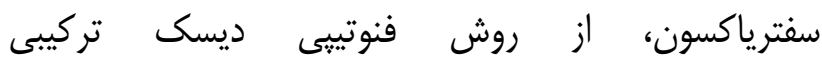
استفاده شد. در اين (Combination Disk Test; CDT)

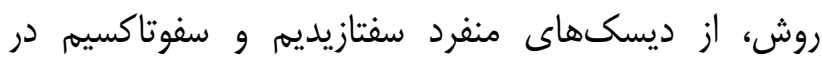

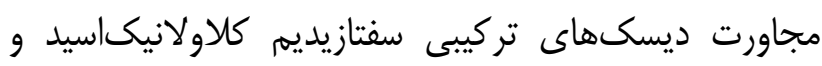
سفوتاكسيم كلاولانيك اسيد (Rosco ايتاليا) در محيط مولر

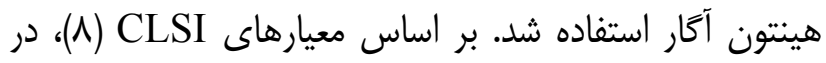
صورتى كه قطر هاله عدم رشد باكترى اطراف ديسكهاى التهاي 
كونههاى سيتروباكتر FN/\& درصد و در گونههاى آسينتوباكتر

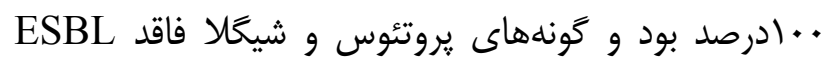

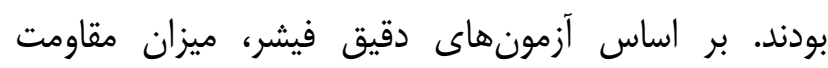

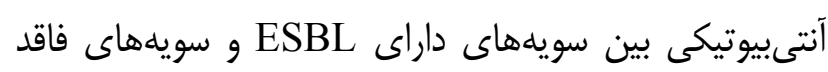
ESBL

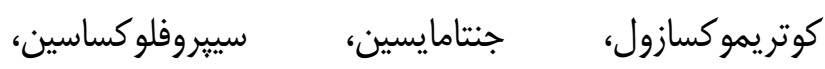
نتايج حاصل از جدول r آنشان داد كه مؤثّرترين

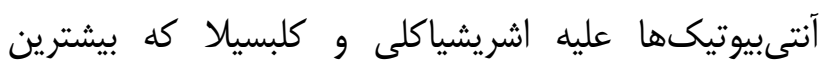

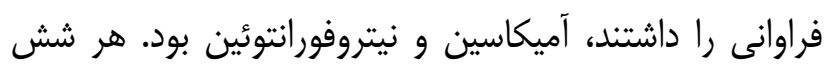

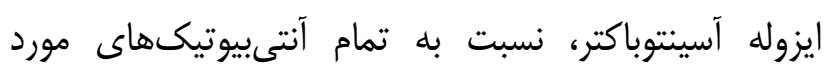

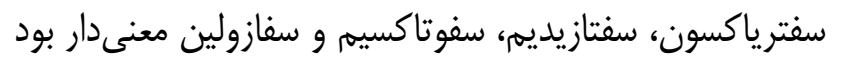

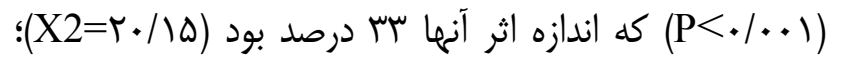

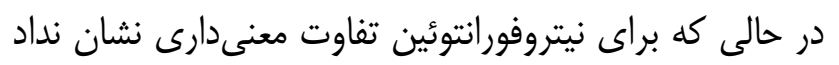
آزمايش مقاوم بودند.

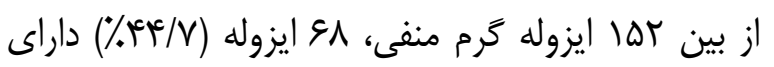
ESBL ESBL

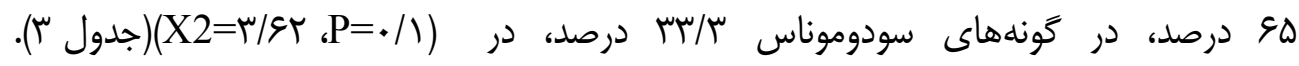
جدول ا - الكَوى مقاومت آنتىبيوتيكى باكترى هاى ترم مثبت جداشده از نمونهاى كلينيك

\begin{tabular}{|c|c|c|c|c|c|c|c|c|}
\hline \multicolumn{8}{|c|}{ آنتى بيوتيكى } & \multirow{3}{*}{ باكترىها } \\
\hline $\begin{array}{l}\text { IPM } \\
\text { تعداد }\end{array}$ & $\begin{array}{l}\text { FOX } \\
\text { تعداد }\end{array}$ & $\begin{array}{c}\text { E } \\
\text { تعداد }\end{array}$ & $\begin{array}{c}\text { P } \\
\text { تعداد }\end{array}$ & $\begin{array}{c}\text { CC } \\
\text { تعداد }\end{array}$ & $\begin{array}{c}\text { CP } \\
\text { تعداد }\end{array}$ & $\begin{array}{l}\text { SXT } \\
\text { تعداد }\end{array}$ & $\begin{array}{l}\text { AM } \\
\text { تعداد }\end{array}$ & \\
\hline (درصد) & (درصد) & (درصد) & (درصد) & (درصد) & (درصد) & (درصد) & (درصد) & \\
\hline$f(19)$ & $f(19)$ & $1 \cdot(\mathcal{E} V / \mathcal{G})$ & $1 \cdot(\mathcal{E} / \mathcal{G})$ & $q(F Y / \Lambda)$ & $f(19)$ & $\Delta(K / \Lambda)$ & $I r(\Delta V / l)$ & استافيلوكوكوس اورئوس \\
\hline $1(11 / 1)$ & $\mathcal{F}\left(\mathcal{c}^{e} / \mathcal{F}\right)$ & $\Delta(\Delta \Delta / \bar{\varphi})$ & $f(F \in / F)$ & $\Gamma(\Psi r / \Gamma)$ & $t(r T / 4)$ & $r(T r / T)$ & $F(F \varphi / F)$ & استافيلوكوكوس إيبدرميديس \\
\hline $1(1 \cdot \cdots)$ & $1(1 \cdots)$ & $1(1 \cdots)$ & $1(1 \cdots)$ & $1(1 \cdots)$ & • & $1(1 \cdot \cdots)$ & $1(1 \cdots)$ & استافيلوكو كوس سايروفيتيكوس \\
\hline $1(1 \cdots)$ & $1(1 \cdots)$ & • & $\cdot$ & . & . & . & $1(1 \cdots)$ & استريتوكو كوس ينومونيه \\
\hline
\end{tabular}

AM: Ampicillin; SXT: Co-trimoxazole; CP: Ciprofloxacin; CC: Clindamycin; P: Penicillin; E: Erythromycin; FOX: Cefoxitin; IPM: Imipenem

جدول r- التَوى مقاومت آنتى بيوتيكى باكترىهاى تَرم منفى جداشده از نمونهاى كلينيكى

\begin{tabular}{|c|c|c|c|c|c|c|c|c|c|c|}
\hline \multicolumn{10}{|c|}{ آنتى بيوتيك } & \multirow{3}{*}{ باكترى ها } \\
\hline $\begin{array}{c}\text { CZ } \\
\text { تعداد }\end{array}$ & $\begin{array}{l}\text { CTX } \\
\text { تعداد }\end{array}$ & $\begin{array}{l}\text { CAZ } \\
\text { تعداد }\end{array}$ & تعداد & $\begin{array}{c}\text { CP } \\
\text { تعداد }\end{array}$ & $\begin{array}{c}\text { GM } \\
\text { تعداد }\end{array}$ & $\begin{array}{l}\text { SXT } \\
\text { تعداد }\end{array}$ & $\begin{array}{l}\text { FM } \\
\text { تعداد }\end{array}$ & $\begin{array}{c}\text { AM } \\
\text { تعداد }\end{array}$ & $\begin{array}{c}\text { AN } \\
\text { تعداد }\end{array}$ & \\
\hline (درصد) & (درصد) & (درصد) & (درصد) & (درصد) & (درصد) & (درصد) & (درصد) & (درصد) & (درصد) & \\
\hline \&) $\left(\Delta \Delta / \digamma^{\leftarrow}\right)$ & $\operatorname{Ft}\left(\varphi^{c}\right)$ & $r(r \cdot)$ & $i q(F / / \Lambda)$ & $r \Delta(r T / V)$ & $r q(T r / \mathcal{G})$ & $9 \vee(9 . / 9)$ & $\wedge(\wedge)$ & $\Delta F(F q / 1)$ & $8(\Delta / \Delta)$ & اشريشياكلى \\
\hline $10(V \Delta)$ & $\pi(\xi \Delta)$ & $11(\Delta \Delta)$ & $\pi(\xi \Delta)$ & $q\left({ }^{5} \Delta\right)$ & $9\left({ }^{5} \Delta\right)$ & $q\left({ }^{*} \Delta\right)$ & $\Delta(\Gamma \Delta / v)$ & $\pi(\xi \Delta)$ & $r(r \cdot)$ & كونههاى كلبسيلا \\
\hline$f(\Delta V / \Lambda)$ & $T(T N / \varepsilon)$ & $1(1) / T)$ & $T(T N / G)$ & $1(11 / T)$ & $T(T N / G)$ & $f(\Delta V / I)$ & • & $r(F T / q)$ & $T(T N / G)$ & كَونهاى سيتروباكتر \\
\hline$f(\xi g / V)$ & $r(\mu / \mu)$ & . & $r(r \Gamma / \Gamma)$ & $1(1 \& / V)$ & - & $r(\Delta \cdot)$ & - & $f(\xi \Leftrightarrow / V)$ & · & كونههاى سودوموناس \\
\hline - & • & - & • & • & - & - & - & - & - & يروتئوس \\
\hline $1(1 \cdots)$ & • & - & . & · & - & $1(1 \cdots)$ & • & $1(1 \cdots)$ & • & شيكلا \\
\hline$q(1 \cdots)$ & $q(1 \cdots)$ & $\varepsilon(1 \cdots)$ & $q(1 \cdots)$ & $q(1 \cdots)$ & $q(1 \cdots)$ & $q(1 \cdots)$ & $1(1 \cdots)$ & $q(1 \cdots)$ & $q(1 \cdots)$ & كونههاى آسينتوباكتر \\
\hline
\end{tabular}

AN: Amikacin; AM: Ampicillin; FM :Nitrofurantoin; SXT: Co-trimoxazole; GM: Gentamicin; CP: Ciprofloxacin; CRO: Ceftriaxone; CAZ: Ceftazidime; CTX: Cefotaxime. CZ: Cefazolin 
جدول ب- مقايسه الكَوى حساسيت آنتىبيوتيكى در سويه هاى تَرم منفى داراى ESBL و فاقد ESBL

\begin{tabular}{|c|c|c|c|c|c|c|c|}
\hline \multirow[b]{2}{*}{ P-Value } & \multicolumn{3}{|c|}{ سويdهاى فاقد ESBL } & \multicolumn{3}{|c|}{ سويههاى داراى ESBL } & \multirow[b]{2}{*}{ آنتىبيوتيك } \\
\hline & $\begin{array}{c}\text { (درصد) تعداد } \\
\text { مقاوم }\end{array}$ & (درصد) تعداد حساس & (درصد) تعداد & 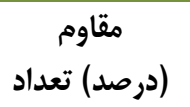 & (درصد) تعداد & (درصد) تعداد & \\
\hline$<\cdot 1 \cdots)^{*}$ & $1(1 / T)$ & $f(r / \Lambda)$ & Vq $(\% 99)$ & IV $(\%$ \% & $r(r / 9)$ & $p q(V r / l)$ & $\mathrm{AN}$ \\
\hline$<\cdot 1 \ldots 1 * *$ & $r)(r \Delta / r)$ & س (Iه/V) & $19(\% \Delta q)$ & Q9 $(M N / 1)$ & $1(1 / \Delta)$ & $V\left(1 \cdot / f^{c}\right)$ & $\mathrm{AM}$ \\
\hline$\cdot / 1 *$ & $\Delta(\xi / 9)$ & $r(\mathcal{F} / T)$ & $\operatorname{sc}(M / q)$ & $q(I V / 9)$ & $r(\Delta / q)$ & qq $(V \& / \Delta)$ & FM \\
\hline$<\cdot 1 \ldots 1 *$ & $r V(\%+4)$ & r (r/q) & $\operatorname{cr}(\Delta T / K)$ & Q & $r(r)$ & $\|(1 \& / V)$ & SXT \\
\hline$<\cdot / \cdots+1 *$ & $r(\Gamma / \mathcal{L})$ & $\Delta(\%)$ & $V D\left(q \cdot / \mathbb{L}^{c}\right)$ & $r \cdot(\Delta N / \Lambda)$ & $\cdot$ & $r \Lambda(F) / T)$ & GM \\
\hline$<\cdot 1 .+1 *$ & $\vee(\Lambda / \mu)$ & $\vee(\Lambda / \Psi)$ & $V \cdot(\Lambda \mu / r)$ & ع (Dr/V) & . & 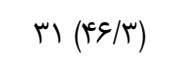 & $\mathrm{CP}$ \\
\hline$<\cdot 1 \ldots 1 * *$ & $r(r / r)$ & $11(1 / س)$ & $V \cdot(\wedge \uparrow / r)$ & $q V(Q \wedge / \Delta)$ & . & $1(1 / \Delta)$ & $\mathrm{CRO}$ \\
\hline$<. / \ldots 1 * *$ & . & $f(r / \Lambda)$ & $\mathrm{Vq}(9 \Delta / \mathrm{T})$ & $r \cdot(\Delta N / \Delta)$ & Ir (IV/g) & $1 \varepsilon(r / \Delta)$ & CAZ \\
\hline$<\cdot \mid \ldots)^{* *}$ & $r(r / r)$ & $q(1 \cdot / 1)$ & $V r(\Lambda \& / V)$ & $9 \Delta(৭ \Delta / \&)$ & $I(1 / \Delta)$ & $r(r / 9)$ & CTX \\
\hline$<\cdot / \ldots 1 *$ & TE (TN/G) & $\mathcal{f}(\mathcal{c} / \Lambda)$ & $\Delta \varepsilon(\varepsilon q / V)$ & $\operatorname{sv}(1 \cdots)$ & . & . & $\mathrm{CZ}$ \\
\hline
\end{tabular}

AN: Amikacin; AM: Ampicillin; SXT: Co-trimoxazole; CP: Ciprofloxacin; CC: Clindamycin; P: Penicillin; E: Erythromycin; FOX: Cefoxitin; IPM: Imipenem

مسئله، حضور باكترىهاى انتروباكترياسيه در مدفوع و احتمال

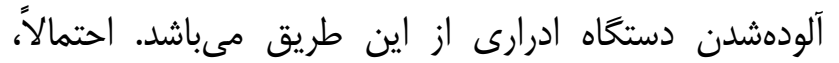

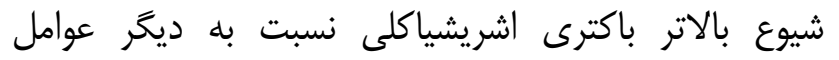
باكتريال عفونت مجارى ادرارى بهعلت توانايى بيشتر باكترى بالهي

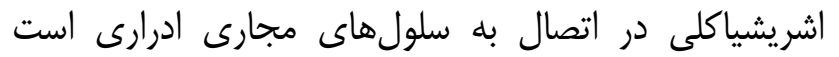

در اين مطالعه، باكترىهاى گرم مثبت بيشترين مقاومت

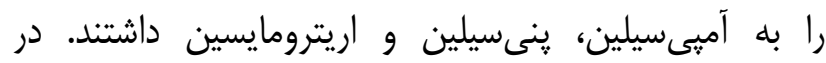

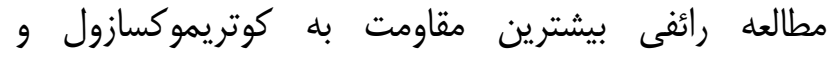
آمبىسيلين و كمترين مقاومت به تتراسايكلين در سويههاى

استافيلوكوكوس اورئوس مشاهده شد (ع)).

باكترىهاى گرم منفى نيز در مطالعه حاضر، بلصورت

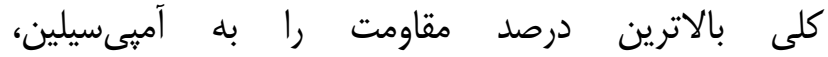
كوتريموكسازول و سفازولين و كمترين مقاومت را به آميكاسين و نيتروفورانتوئين داشتند كه با مطالعات برارى سوادكوهى و همكاران و محمدى و همكاران همخوانى دارد

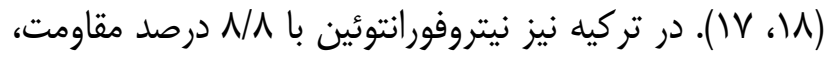
بلهعنوان حساسترين آنتىبيوتيك شناخته شد (19). در برزيل

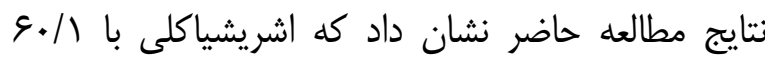
درصد، استافيلوكوكوس اورئوس با ه/ 11 درصد و كونهانهاى كلبسيلا با / / 1 درصد بيشترين فراوانى را داشتند. در مطالعه

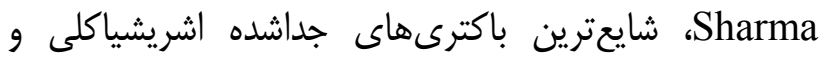
استافيلوكوكوس اورئوس بود كه با نتايج مطالعه حاضر همسو مىباشد (9). در بيشتر مطالعات انجامشده نيز اشريشياكلى بيشترين شيوع را دارد، اما ترتيب قرارگيرى ساير پاتوزنها بعد از آن در مقالات مختلف متفاوت ذكر شده است؛ به عنوان مثال، در مطالعاتى كه توسط ملازاده و همكاران، امين و همكاران و عبداللمى و همكاران انجام شده، كلبسيلا بلعنوان دومين عامل شايع بيان شده است (با-+(). در مطالعه اسماعيلى و همكاران بعد از اشريشياكلى، انتروباكتر و و استافيلوكوكوس سايروفيتيكوس بيشترين شيوع را داشتند (r) Alos و همكاران در اسپانيا، انتروباكترياسه را جزء اصلىترين عوامل عفونت مجارى ادرارى معرفى نمودند كه

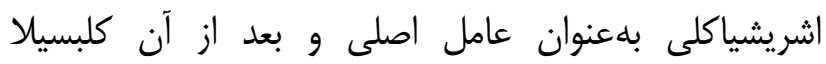

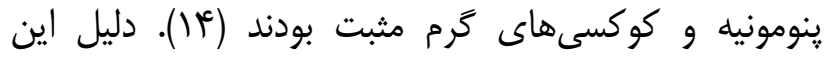


ESBL

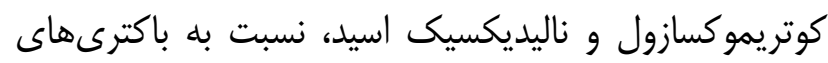

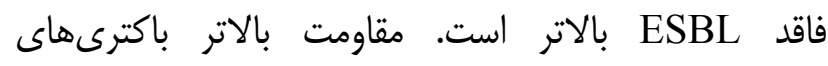

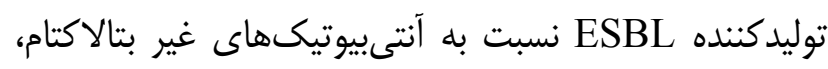

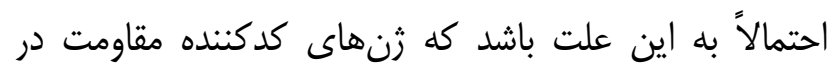

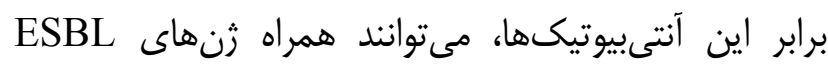

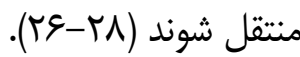

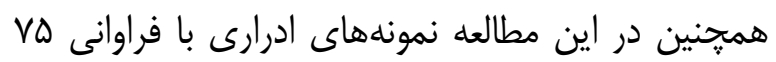

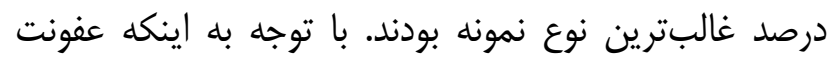

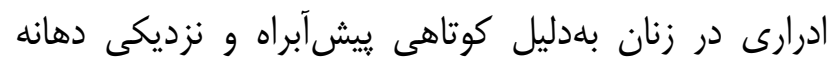

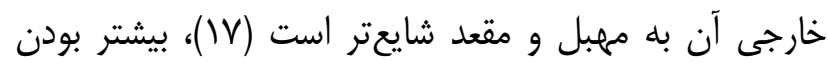

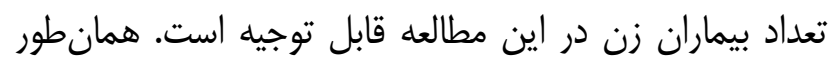
كه در مطالعات انجامگرفته توسط عيسىيور و و همكاران، حجازى و همكاران و رائفى و همكاران تعداد زنان مبتلا به ونه

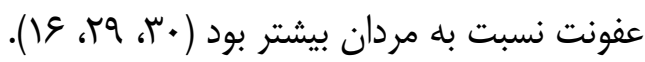

\section{نتيجه كيرى}

در اين مطالعه شايعترين باكترىهاى ايجادكننده عفونت،

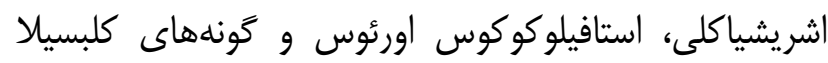

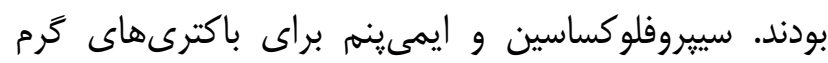

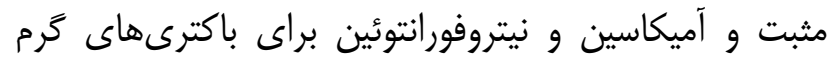

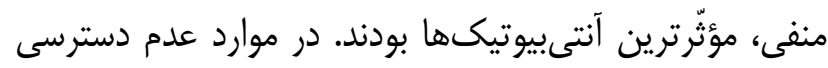

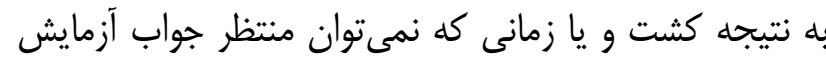

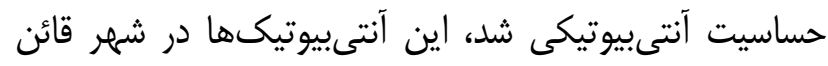

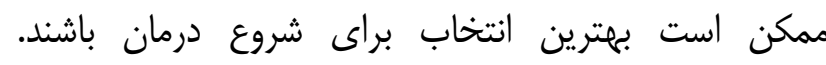

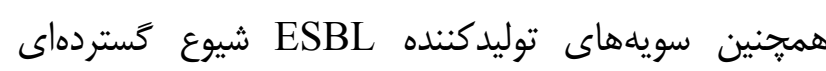
داشتند؛ بنابراين هايش مستمر و شناسايى سريع اين سويهها

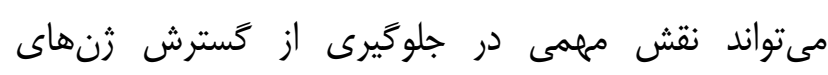
بتالاكتاماز وسيع الطيف داشته باشد.

\section{تقدير و تشكر}

اين مقاله بركرفته از طرح تحقيقاتى به شماره س. بـ
بيشترين مقاومتها به آمبىسيلين (هDه٪) و بعد از آن به

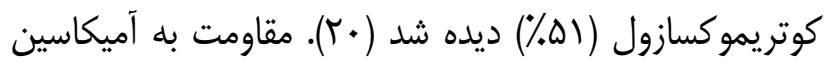

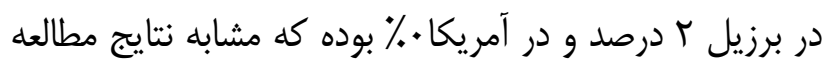

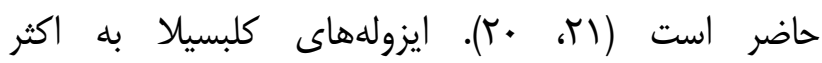

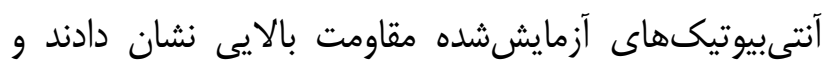

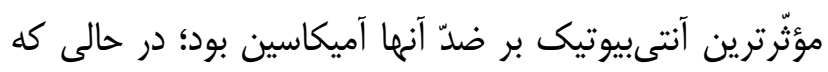
در مطالعه انجامشده توسط رائفى بيشترين حساسيت را بيه

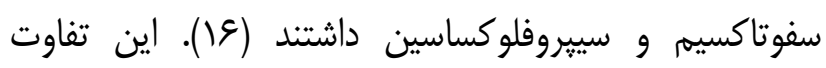

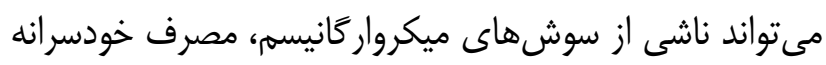

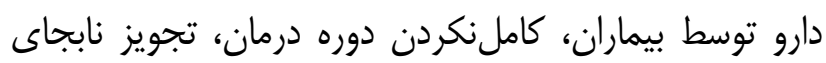

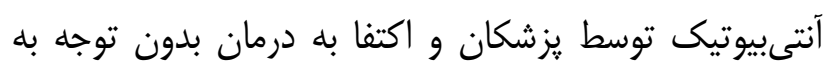
نتيجه كشت و آنتىبيوكرام باشد.

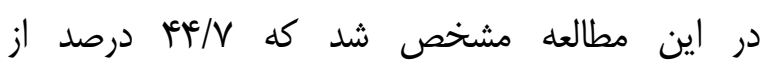

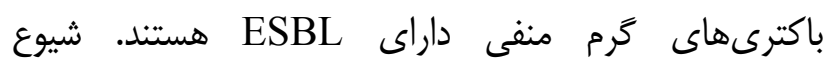
اشريشياكلى توليدكننده ESBL در مطالعه مقنّى و همكاران

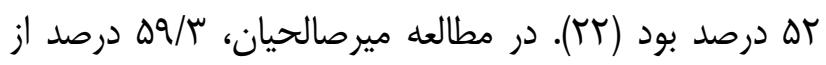

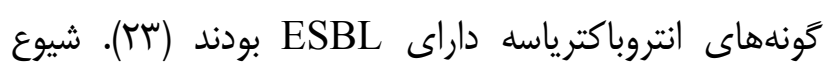

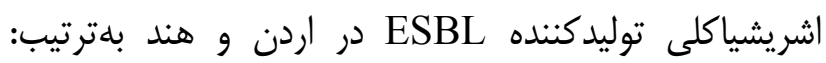

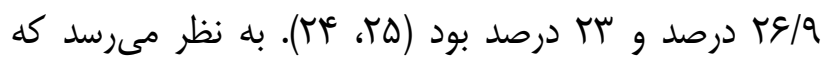

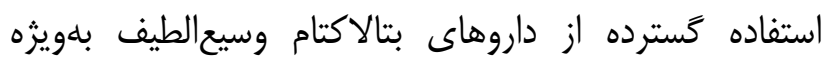

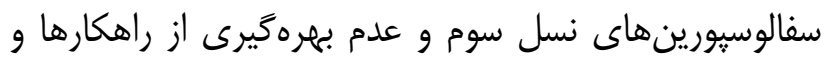

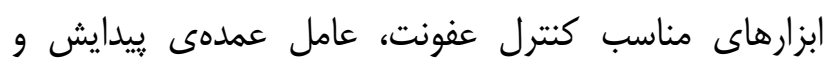

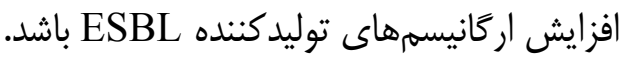
يكى از مسائل مهم در مورد باكترىهاى توليدكنئده توليده

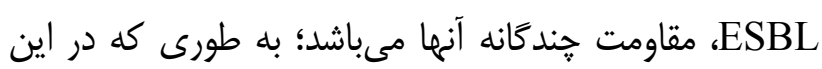

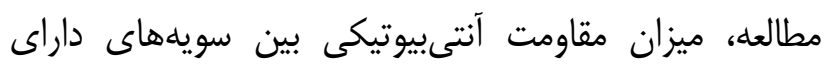
ESBL

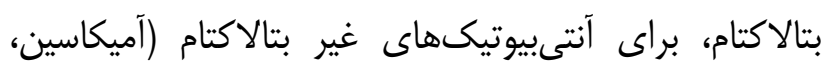
كوتريموكسازول، جنتامايسين و سييروفلوكساسين) نيز معنادار

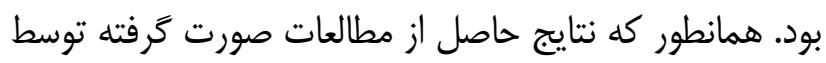

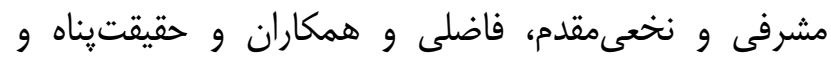

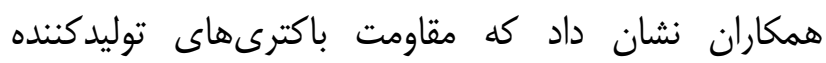




$$
\begin{aligned}
& \text { مىباشد. نويسندكان مقاله بر خود لازم مىدانند كه از تضاد منافع: }
\end{aligned}
$$

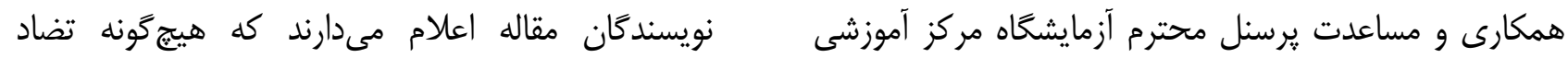

$$
\begin{aligned}
& \text { و درمانى شرلداى قاين و معاونت محترم يزوهشى دانشخاه منافعى در يثوهش حاضر وجود ندارد. } \\
& \text { علوم يزشكى بيرجند بله خاطر تأمين هزينها و همكارى در } \\
& \text { اجراى اين مطالعه، تشكر و قدردانى نمايند. } \\
& \text { منابع: }
\end{aligned}
$$

1- Taheri N, Abtahi H, Amozande-Nobaveh A, Zarinfar N, Ghaznavi-Rad E. The antibiotic resistant determinant of pathogenic bacteria isolated from medical equipment and hospital environment in Valiasr Hospital, Arak, 2013. J Mazandaran Univ Med Sci. 2014; 24(114): 60-73. [Persian]

2- Hosseini MJ, Ranjbar R. A case report of Septicemia due to Pseudomonas aeruginosa and Acinetobacter in a multiple trauma Patient. J Ilam Univ Med Sci. 2008; 16(2): 16-20. [Persian]

3- Davies J, Davies D. Origins and evolution of antibiotic resistance. Microbiol Mol Biol Rev. 2010; 74(3): 417-33. doi: 10.1128/MMBR.00016-10

4- Sharifian M, Karimi A, Tabatabaei SR, Anvaripour N. Microbial sensitivity pattern in urinary tract infections in children: a single center experience of 1,177 urine cultures. Jpn J Infect Dis. 2006; 59(6): 380-2.

5- Thirapanmethee K. Extended spectrum $\beta$-lactamases: critical tools of bacterial resistance. Mahidol Univ J Pharm Sci. 2012; 39(1): 1-8.

6- Vatopoulos A, Philippon A, Tzouvelekis LS, Komninou Z, Legakis NJ. Prevalence of a transferable SHV-5 type $\beta$ lactamase in clinical isolates of Klebsiella pneumoniae and Escherichia coli in Greece. J Antimicrob Chemother. 1990; 26(5): 635-48. DOI: 10.1093/jac/26.5.635

7- Forbes BA, Sahm DF, Weissfeld AS. Study Guide for Bailey \& Scott's Diagnostic Microbiology. $12^{\text {th }}$ ed. Missouri: Mosby Elsevier; 2007. pp: 842-55.

8- CLSI. Performance Standards for Antimicrobial Susceptibility Testing. 26th ed. CLSI supplement M100S. Wayne, PA: Clinical and Laboratory Standards Institute; 2016.

9- Sharma I, Paul D. Prevalence of community acquired urinary tract infections in Silchar Medical College, Assam, India and its antimicrobial susceptibility profile. Indian J Med Sci. 2012; 66(11-12): 273-9. doi: 10.4103/00195359.115749 .

10- Abd Elahi A, Mehrazma M. Evaluation of antibiotic susceptibility \& resistancy in urinary infections Imam Khomeini hospital complex-Tehran. Pars J Med Sci. 2009; 7(3): 59-66. [Persian]

11- Amin M, Mehdinejad M, Pourdangchi Z. Study of bacteria isolated from urinary tract infections and determination of their susceptibility to antibiotics. Jundishapur J Microbiol. 2009; 2(3): 118-23. [Persian]

12- Molazade A, Gholami MS, Shahi A, Najafipour S, Mobasheri F, Ashraf Mansuri JA, et al. Evaluation of Antibiotic Resistance Pattern of Isolated Gram-Negative Bacteria from Urine Culture of Hospitalized patients in Different Wards of Vali-Asr Hospital in Fasa During the Years 2012 and 2013. J Fasa Univ Med Sci. 2014; 4(3): 275-83. [Persian]

13- Esmaeili R, Hashemi H, Moghadam Shakib M, Alikhani M, Sohrabi Z. Bacterial Etiology of Urinary Tract Infections and Determining their Antibiotic Resistance in Adults Hospitalized in or Referred to the Farshchian Hospital in Hamadan. J Ilam Univ Med Sci. 2014; 21(7): 281-7. [Persian]

14- Alós JI, Serrano MG, Gómez-Garcés JL, Perianes J. Antibiotic resistance of Escherichia coli from communityacquired urinary tract infections in relation to demographic and clinical data. Clin Microbiol Infect. 2005; 11(3): 199203. DOI: $10.1111 / \mathrm{j} .1469-0691.2004 .01057 . \mathrm{x}$

15- Washington CW, Stephen A, Janda W. Koneman's color atlas and textbook of diagnostic microbiology. England: Williums \& Wilkins, Ltd; 2006. 
16- Raefi A, Amiri Kojouri S, Rjabi MH, Naghi Pour E, Mokarrari S, Arab Sarhadi N, et al. The study of prevalence and antimicrobial susceptibility of bacterial isolated from urinary tract in outpatients admitted to Shohada hospital of Gonbad city. NavidNo. 2016; 19(62): 41-8. doi: 10.22038/nnj.2016.7421 [Persian]

17- Mohammadi S, Ramazanzadeh R, Zandi S, Rouhi S, Mohammadi B. Isolation and antibiotic resistance pattern determination of bacteria causing urinary tract infections in patients to Sanandaj Tohid hospital 2013-2014. Zanko J Med Sci. 2015; 16(50): 55-62. [Persian]

18- Barari Sawadkouhi R, Sorkhi H, Pournasrollah M, Bijani A, Babazadeh N, Baleghi Damavandi S. Antibiotic resistance of bacteria causing urinary tract infections in children hospitalized in Amirkola Children Hospital during 2010-2011. J Babol Univ Med Sci. 2013; 15(5): 89-94. [Persian]

19- Kurutepe S, Surucuoglu S, Sezgin C, Gazi H, Gulay M, Ozbakkaloglu B. Increasing antimicrobial resistance in Escherichia coli isolates from community-acquired urinary tract infections during 1998-2003 in Manisa, Turkey. Jpn J Infect Dis. 2005; 58(3): 159-61.

20- Guidoni EBM, Berezin EN, Nigro S, Santiago NA, Benini V, Toporovski J. Antibiotic resistance patterns of pediatric community-acquired urinary infections. Braz J Infect Dis. 2008; 12(4): 321-3.doi: 10.1590/S141386702008000400013

21- Lutter SA, Currie ML, Mitz LB, Greenbaum LA. Antibiotic resistance patterns in children hospitalized for urinary tract infections. Arch Pediatr Adolesc Med. 2005; 159(10): 924-8. doi: 10.1001/archpedi.159.10.924

22- Moghanni M, Ghazvini K, Farsiani H, Namaei MH, Derakhshan M, Yousefi M, et al. High prevalence of sequence type 131 isolates producing CTX-M-15 among extended-spectrum $\beta$-lactamase-producing Escherichia coli strains in northeast Iran. J Glob Antimicrob Resist. 2018; 15: 74-8. doi: 10.1016/j.jgar.2018.05.016.

23- Mirsalehian A, AkbariNakhjavani F, Peymani A, JabalAmeli F, Mirafshar SM, Hamidian M. Frequency of extended spectrum $\beta$-Lactamase producing Enterobacteriaceae in intensive care units. Tehran Univ Med J. 2008; 65(1): 33-8. [Persian]

24- Al-Agamy MH, Shibl AM, Hafez MM, Al-Ahdal MN, Memish ZA, Khubnani H. Molecular characteristics of extended-spectrum $\beta$-lactamase-producing Escherichia coli in Riyadh: emergence of CTX-M-15-producing E. coli ST131. Ann Clin Microbiol Antimicrob. 2014; 13: 4. doi: 10.1186/1476-0711-13-4

25- Hussain A, Ewers C, Nandanwar N, Guenther S, Jadhav S, Wieler LH, et al. Multiresistant uropathogenic Escherichia coli from a region in India where urinary tract infections are endemic: genotypic and phenotypic characteristics of sequence type 131 isolates of the CTX-M-15 extended-spectrum- $\beta$-lactamase-producing lineage. Antimicrob Agents Chemother. 2012; 56(12): 6358-65. doi: 10.1128/AAC.01099-12.

26- Haghighat Panah M, Amirmozafari N, Faezi M, Shenagari M. Surveying of antibiotic resistance pattern and frequency rate of blaTEM in the ESBLs producing E. coli isolated in Rasht. J Ilam Univ Med Sci. 2014; 22(4): 180-9. [Persian]

27- Fazeli H, Hoseini MM, Mohammadi Ghalaei P. Frequency and resistance pattern of extended spectrum beta lactamase producing Escherichia coli in clinical specimen of Alzahra hospital in Isfahan, Iran, 2007. J Shahrekord Univ Med Sci. 2009; 10(4): 58-64. [Persian]

28- Moshrefi Sh, Nakhaee Moghaddam M. Determiming the antibiotic resistance pattern of urinary isolates of Escherichia coli and prevalence of extended spectrum B-Lactamases (ESBLS) among them. J Sabzevar Univ Med Sci. 22010; 16(4): 228-33. [Persian]

29- Hejazi F, Ahanjan M, Akha O, Salehiyan M. Phenotypic Study of Urinary Tract Infection Producing Bacteria and Antibiotic Resistance Pattern in Diabetic Patients. J Mazandaran Univ Med Sci. 2018; 28(163): 38-46. [Persian]

30- Isapour A, Asadian L, Ashbin F, Akha O. Prevalence of asymptomatic urinary tract infection in diabetic patients. J Mazandaran Univ Med Sci. 2015; 25(125): 95-101. [Persian] 